Psychological Medicine, 1985, 15, 717-726

Printed in Great Britain

EDITORIAL

\title{
Effects of early nutrition on neurological and mental competence in human beings ${ }^{1}$
}

Nutrition and hunger have social, psychological and physical connotations, all documented since the first written records. Among documents of our own time that draw attention to these connotations are: Sorokin's (1975) volume on starvation in post-revolutionary Russia; the SHAEF report on the famine in the Netherlands in the immediate aftermath of World War II (Burger et al. 1948); the observational studies made by physicians during the siege of the Warsaw ghetto in World War II (recently made available in English; Winick, 1979); and the Swedish Nutrition Foundation Symposium on famine (Blix et al. 1971). The encyclopaedic Human Starvation (Keys et al. 1950) contains numerous historical sources and, in addition, provides details on behavioural effects from experimental and quasi-experimental studies of human starvation. These studies are a bridge to modern scientific approaches. In the latter genre we must place a moving study by Widdowson (1951), appropriately entitled 'Mental contentment and physical growth'. Although her paper deals with physical growth and appeared more than 30 years ago, it aptly illustrates what will be a main interpretative line of this review.

Widdowson reported a 12-month nutritional experiment carried out in occupied Germany after World War II. The children in two orphanages, 'Bienenhaus' and 'Vogelsnest', were started on identical diets. Unexpectedly, identical diets did not result in identical weight gain. At the end of the first six months, the children in Bienenhaus had gained consistently less than those in Vogelsnest. For the second six months, in a pre-determined cross-over design, the experimenters supplemented the original experimental diet in Vogelsnest, where the children were already doing better. Those in Bienenhaus continued unsupplemented with the initial diet. Unexpectedly again, the gains in weight were reversed. The Vogelsnest children failed to maintain their previous advantage, despite their supplemented diet. The Bienenhaus children, still on the original unsupplemented diet, began to make greater gains, and at the end of the second six months had overtaken the Vogelsnest children.

The puzzled investigators finally discovered that the matron of Bienenhaus, the strict and authoritarian Fräulein Schwartz, had been transferred to Vogelsnest at the time of the cross-over, half way through the experiment. Throughout the experiment, it thus turned out, the same matron had been in charge of the children who did not thrive. The strict regime imposed by Fräulein Schwartz was in marked contrast to that of the matron she replaced at Bienenhaus, and also of the matron who succeeded her at Vogelsnest: both these other matrons were kind and motherly women.

The part played by the relations of the children with the mother-substitute was clearly central (Susser \& Watson, 1971). This part was further emphasized by the divergent patterns of the growth curves of eight children who were Fräulein Schwartz's 'favourites'. She had moved these eight children with her from Bienenhaus to Vogelsnest. During both the first six months in Bienenhaus, and the second six months in Vogelsnest, the growth of the eight favourites was superior to that of the other children with whom they lived. Widdowson epitomized her study in a Biblical quotation: 'Better is a dinner of herbs where love is, than a stalled ox and hatred therewith'.

This study underlines a truism. From the moment a child is born it enters a social milieu, in which it gives and receives, in which it acts and responds. From a wealth of observations we can be sure

\footnotetext{
1 This is a revised version of a paper presented at the National Institute of Mental Health Workshop 'Dietary and nutritional intervention in preventive mental health', held in Rockville, Maryland, USA, 5-6 November 1982. Address for correspondence: Professor Zena Stein, Gertrude H. Sergievsky Center, Columbia University, and New York State Psychiatric Institute, 630 West 168th Street, New York, NY 10032, USA.
} 
that mental growth no less than physical growth will reflect the social and psychological milieu. It is therefore likely to be difficult, and even misleading, to study diet as an isolated variable separated from the social milieu. The attempt to isolate nutritional from social effects must be made, but one should interpret these with due caution.

The first of two pervasive and frustrating problems of design in this field is this confounding of nutritional with social variables. The second is the precise measurement of the nutritional exposure over time. In this crucial matter of the measurement of nutrient intake a modest advantage of studies of prenatal nutrition is that attention can be confined to the mother. Once the child passes into the postnatal phase the number of confounding variables multiplies. But most will agree that, in the acquisition of nutrients, the foetus can exercise little initiative. Since only the mother is truly an active party in the dyad, only she must be monitored.

In the following review we shall attempt to relate acute and chronic nutritional deprivation to mental competence. Studies seeking to evaluate the connections between nutrition and mental competence have to take account of several issues (Stein \& Kassab, 1970; Lloyd-Still, 1976b):

(1) The timing and the duration of the nutritional exposure in relation to foetal development.

(2) The degree and the type of the nutritional exposure - i.e. the severity of malnutrition, and the dietary constituents affected.

(3) The nature of the outcome measures: in particular, whether the degree of mental retardation is mild or severe; whether the cognitive effects are global or limited to specific functions or abilities; whether there are associated behavioural, neurological or other disorders.

(4) The social context: whether the family and social milieu explains, mediates, interacts with or counteracts the nutritional insult.

With regard to timing and duration of the nutritional exposure, no single parameter of brain growth, biochemical or cellular, and no single timetable of development, is a sufficient index of the structural and functional changes of the developing human brain (Chase, 1976). Available biochemical indices of brain growth do not discriminate between such cell types as neurones and glia, and these different cell types proliferate or enlarge asynchronously. The growth of cortex and cerebellum, and the accumulation of lipids and proteins, are also asynchronous. Therefore, the general rule that tissues and organs are especially vulnerable to an adverse milieu during the phase of maximum growth is not easily applied in practice. No narrow critical period can capture at once the vulnerability in rapid growth common to all cells, tissues, and biochemical constituents.

Instead of focusing on one critical or sensitive period, therefore, we propose to use a framework of developmental timing that separates four phases of growth in the individual organism.

(1) The periconception phase begins with follicular development of the ovum: it covers the two weeks before fertilization and, after fertilization, blastocyst development up to implantation on about the eighth day.

(2) The embryonic phase begins with implantation and continues through the first trimester: it covers the second to the twelfth week after conception, roughly the period of organogenesis.

(3) The foetal phase extends through the second and third trimester and continues to term: in the second trimester, hyperplasia of neurones occurs; in the third trimester, hypertrophy of neurones and hyperplasia of glia.

(4) The postnatal phase begins at birth when the infant becomes an actor in a social milieu, and extends into the second year of life; it covers a period of continuing rapid brain growth, the laying down of myelin, arborization and the completion of synapse formation.

\section{PERICONCEPTION}

On the whole, knowledge of this phase relates to specific metabolic problems. Three instances are iodine deficiency, insulin deficiency, and hyperphenylalaninemia.

(a) Iodine deficiency in the mother before conception is associated with an atypical form of cretinism in the offspring (Hetzel \& Hay, 1979). The child is small, dull or moderately retarded, often deaf, and with delayed motor development; there may be spasticity and sometimes hemiparesis. 
Prophylactic randomized controlled trials show that iodized oil administered to the mother before conception prevents the condition. Once pregnancy is clearly established, and also after birth, treatment for the mental and neurological impairments seems to be far less effective (although growth might still be stimulated).

(b) Uncontrolled insulin-dependent diabetes in the mother also seems to affect development in the phase before pregnancy is established and recognized (Miller et al. 1981). In the weeks before the first missed period, high blood sugar levels (as indicated by the glycosylate test) appear to be associated with a raised risk for congenital malformations of a very specific type, and including mental retardation. Although, during the remaining foetal phase, blood sugar level influences the growth and survival of the foetus, it does not seem to affect the risk of malformations and mental retardation.

(c) Phenylketonuria in a pregnant woman exposes her offspring in utero to hyperphenylalaninemia. The offspring have usually experienced intrauterine growth retardation; mental retardation is a regular outcome, often together with microcephaly and congenital heart defects. The dietary control of phenylalanine levels during pregnancy has not been shown to prevent these disorders, but case reports hold out the hope that control before conception may do so (Lenke \& Levy, 1980).

\section{THE EMBRYONIC PHASE}

In this phase, evidence of two quite different kinds - one involving acute and the other chronic nutrient deficiencies - suggests a role for nutrition in the developmental morphology of the central nervous system.

First, acute starvation in the mother has effects both on the length of gestation and on organogenesis. Thus exposure to the Dutch famine, in the first trimester of pregnancy only, had several adverse outcomes. There was an excess of premature infants of very low birthweight, and also an excess of stillbirths and first week deaths (Stein et al. 1975). We do not know whether these were malformed. However, among the causes of subsequent deaths in those exposed in the first trimester, an excess was attributed to disorders of the central nervous system; and among male survivors at the age of nineteen there was an excess of neural tube defects and cerebral palsy (Stein et al. 1976). Among these survivors exposed in the embryonic phase, there was also an excess of obesity (Ravelli et al. 1976), a result since replicated experimentally in rats (Jones \& Friedman, 1982).

Secondly, a more chronic exposure to prenatal dietary deficiency has for some years been proposed as a cause of neural tube defects (spina bifida and anencephaly). The hypothesis has seemed plausible in the light of social, geographical and temporal variation. In Britain, and in the United States, this disorder of organogenesis has been more common among the poorer classes, and in the US frequency reached a peak during the great depression of the 1930s (Edwards, 1958; Yen \& MacMahon, 1968). Towards the end of World War II in Germany (Eichman \& Gesenius, 1952), as well as in the Netherlands (Stein et al. 1975, 1976), severe food shortage was associated with a rise in incidence. Ethnic variation (high frequency in Celts, low in Africans) may indicate that some groups are more susceptible than others to the same environmental insults (Elwood, 1972).

Lately, more direct evidence has added plausibility to the dietary hypothesis. Dietary supplements of 'multivite and iron', given to women with an affected child in anticipation of their next pregnancy, seem to have reduced the risk of recurrence as compared with non-randomized controls who were not given the special supplement before their pregnancy (Smithells et al. 1980). (Parenthetically, one must note potential problems with the comparability of these controls (Laurence et al. 1980).) Some subsequent reports also support the hypothesis. Whether this presumed protection is conferred before conception, or during the periconception phase, or in the embryonic phase before the neuropore closes at the 28 th day of gestation, is uncertain (Mulinaire et al. 1981). We discuss the condition here because the effect is on organogenesis, and hence acts upon development during the embryonic phase, even if it might arise earlier.

With regard to these several forms of nutritional or metabolic imbalance very early in pregnancy, we note that, in two of the four instances (disorders with insulin-dependent diabetes, and neural 
tube defects), one does not anticipate effects that will manifest in all exposed foetuses. In other words, we assume individual vulnerability, perhaps related to a threshold of genetic or other susceptibilities in the mother and offspring.

In the third and fourth instances, hyperphenylalaninemia and preconceptional iodine deficiency, there are grounds for expecting manifestations in all the offspring. With iodine deficiency, all the children born of a group of untreated mothers in New Guinea showed psychometric deficits, when compared with children of mothers randomly assigned to iodized-oil injections before conception (Connolly et al. 1979). More recently, work in an Indonesian village on the age of walking (E. Dulberg, personal communication) showed a population-wide delay in motor development. Thus the cretinous child represents the tip of an iceberg.

Iodine deficiency is the most clear-cut human example of a prenatal dietary disorder which directly affects neurological and mental function. Large tracts of the world are iodine deficient and at high risk: the Himalayas, New Guinea, Indonesia, the Drakensberg in South Africa, and Switzerland.

\section{THE FOETAL PHASE}

Evidence of the effects of nutrition in the foetal phase is of three kinds: it comes from studies of acute starvation, from studies of chronic maternal malnutrition, and from studies of nutritional supplementation in mothers presumed to be chronically malnourished.

A starting point for the exploration of this phase (and the place where, in the developed world, the real clinical interest lies) has been the widespread association of poor maternal nutrition with low birthweight and, in turn, the association of low birthweight with depressed mental competence. The relation of these three variables, however, can be made to fit several causal pathways.

First, let us consider the initial segment of the pathway, leading from prenatal maternal nutrition to birthweight. The strongest and most substantial effects of nutrition on birthweight have been demonstrated during periods of acute starvation in World War II, especially by Antonov's (1947) observations during the 900 days of the Leningrad siege, and Smith's (1947) classic observations in the aftermath of the Dutch famine. We ourselves further elaborated the experience of the Dutch famine, and found a maximum effect of about 9-10\% (300-400 g) (Stein et al. 1975). All dimensions of foetal growth were affected, including head circumference (although to a lesser degree than birthweight and placental weight). The fall in birthweight was followed by a sharp rise in mortality up to three months of life.

With regard to chronic malnutrition, a gradient of rising frequency of low birthweight is invariably found with descent down the social scale. In the Third World, low birthweight is especially prevalent in rural areas that suffer from serious nutritional deficiencies made manifest by stunting, by the stigmata of poor nutrition, and by a high frequency of acute nutritional failure syndromes in infants (marasmus and kwashiorkor). If this form of low birthweight is purely nutritional in origin, however, then birthweight has proved remarkably refractory to attempts to accelerate foetal growth by nutritional means. In rigorous experimental studies, supplementation of the maternal diet during pregnancy has at best produced a modest increment in birthweight. In malnourished mothers, the average increment in birthweight of the offspring of supplemented mothers has reached 60 or $70 \mathrm{~g}$ (in a main study confounding of the relationship by length of gestation remains possible (Habicht et al. 1974a)); in the North American poor it has been nearer $40 \mathrm{~g}$ (Rush et al. 1980). These increments may be compared with the $200 \mathrm{~g}$ of birthweight that are lost by maternal smoking during pregnancy.

When the prenatal supplements contain a high concentration of protein, moreover, the risk of adverse effects cannot any longer be ignored. In the randomized controlled trial of prenatal supplementation in New York, such supplements significantly retarded foetal growth; there was also an excess of premature infants with a high risk of neonatal death. With regard to foetal growth, it is now clear that other studies support this unhappy result. In eight instances (culled from all available sources) birthweight after high prenatal protein supplementation could be compared with birthweight in a control group: in seven of the eight, birthweight was lower in the high protein group (Rush, 1982). 
For the purpose of raising birthweight by means of nutritional supplements, then, a high protein concentration is risky. A balanced protein-calorie supplement does better, although the increment in birthweight is modest. At a population level, however, where there is widespread chronic malnutrition such gains are likely to improve perinatal mortality rates (Habicht et al. 1974a).

We turn now to the second leg of the causal pathway: our question now is whether such gains in birthweight will improve the mind. The relation between birthweight and subsequent mental performance has proved to be a complex one. Several pathways must be considered.

First, in one sequence, a common cause gives rise both to low birthweight and to mental impairment. Thus, in some forms of mental retardation associated with low birthweight, a cause such as a chromosomal anomaly is the antecedent of intrauterine growth retardation on the one hand, and mental retardation on the other.

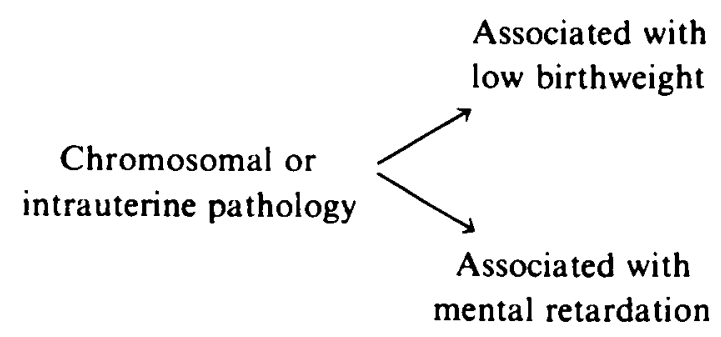

For the purposes of elucidating the causal relationships of prenatal nutrition and subsequent development, this model has no salience. It does have salience, however, in the interpretation of the association. If the contribution of cases of this kind is not allowed for, a true causal association will be spuriously inflated.

In a second sequence, some factor (which might possibly be malnutrition among others) gives rise to marked prematurity and very low birthweight. Very low birthweight infants $(\leqslant 1500 \mathrm{~g})$ are undoubtedly at raised risk of mental retardation and cerebral palsy, and their prematurity, immaturity and vulnerability may underlie that risk. Such infants comprise about $1 \%$ of births in New York City. In the 1960 s, their risk for severe mental retardation was about $4-5 \%$ : that is, in the general population of births they comprise no more than $0 \cdot 5 / 1000$. These infants almost invariably have had severe anoxia and accompanying neurological damage.

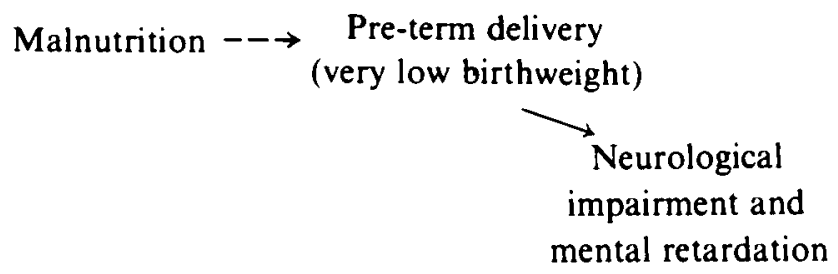

In this sequence the contribution of maternal diet to the incidence of pre-term low birthweight offspring is not likely to be great. Thus, exposure to the Dutch famine during the foetal phase shortened gestation by an average of only four days. Among chronically malnourished populations, supplementation during pregnancy has barely increased the mean duration of gestation. In post-war Japan, although economic development including overall dietary improvement was associated with a rise in mean birthweight in hospital births, no increase in duration of pregnancy was detectable (Gruenwald, 1967).

A third sequence revolves around the central issue of the direct association of depressed birthweight with depressed mental performance (and/or mild mental retardation). This hypothesis stems in part from the association of both low birthweight and poor mental performance with poverty and poor dietary circumstances. This third model is of malnutrition leading to foetal growth 
retardation - a retardation that includes the brain and results in an irreversible depletion of brain cell number - followed by the postnatal depression of mental function (Winick \& Noble, 1966).

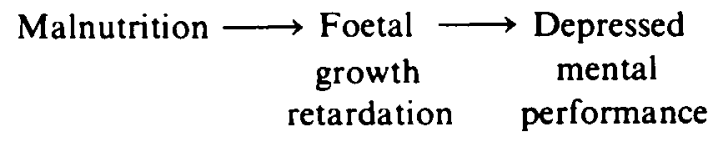

The animal experiments that support this model produced their effects through acute nutritional deprivation - usually of protein - applied during the period of maximum brain growth. This is precisely the model subjected to test - and rejected - by the Dutch Famine Study (Stein et al. 1975). Records of infants born around the famine period confirm that, as in the animal experiments, foetal exposure to famine in the third trimester produced marked foetal growth retardation in all dimensions, including retarded growth of the head. In a complete national population of the surviving 19-year-old men, however, such famine exposure produced virtually no detectable effect on either mental or physical health, with one exception: there was a lower rate of obesity, again in contrast with the effect mentioned above, of first trimester famine exposure in raising the rate of obesity (Ravelli et al. 1976).

In relation to the Dutch Famine Study it can be objected, as we ourselves were the first to do, that for the health of the world at large the more relevant circumstance is not acute starvation and famine but chronic malnutrition. The available evidence, however, does not support the idea that chronic maternal malnutrition during the foetal phase produces manifest effects on measures of cognition, any more than does acute starvation, except in one respect. This evidence derives from experimental studies of diet supplementation in Bogota, Colombia (Waber et al. 1981), and from our own study in New York (Rush et al. 1980).

The exceptional finding is that supplementation with high protein during the foetal phase has appeared to produce highly specific effects on attention, notably the speed of habituation and dishabituation to visual or tactile stimuli. The result is one of the firmer in the literature on the mental effects of nutritional supplementation, having been found - not exactly in the same form - in two randomized trials in human beings and one in primates. The effect is apparently direct, and is not mediated by foetal growth or birthweight. Thus, in the New York study, the other psychometric measures of development all correlated with each other and with physical size (both at birth and at one year of age) but not with the nutritional supplement. In contrast, the habituation measure correlated neither with the other psychometric measures nor with physical growth, but only with the high protein supplement.

There remains in the foetal phase a fourth possible causal model. This model attributes the influence of malnutrition on birthweight to the inhibition of the mother's growth during childhood. Thus population-wide increases in mean birthweight have been concurrent with improvement in nutrition and growth. The prime example, already cited, is Japan in the post World War II period (Gruenwald, 1967). The work of Baird and colleagues in Aberdeen suggests that the change in birthweight could be mediated by an increase in maternal size (Illsley, 1955). The Japanese experience, taken together with the earlier observations of Baird and associates in Scotland, indicates a pathway, aside from nutrient intake directly related to pregnancy, by which the nutrition of the mother over the long-term could be a determinant of birthweight (Thomson, 1956). However, it is not possible to determine whether such an accession in birthweight improves cognitive function. We can be sure that the postnatal milieu of the affected children would also have changed. The task of separating changes over time in the childhood nutrition of mothers from changes over time in the social environment may, as yet, be beyond us. 


\section{THE POSTNATAL PHaSe}

Prenatal and early postnatal effects are difficult to separate. We have noted that the idea of a critical prenatal and early postnatal period of rapid brain cell proliferation, during which nutritional deprivation may cause irrevocable damage, is derived from experimental biochemical studies of brain cell constituents (Winick \& Noble, 1966). More recent histopathological studies suggest that the phase of rapid growth is of longer duration than was first thought. The acceleration that starts in mid-trimester continues well into the second year of postnatal life. A revised hypothesis proposes that this whole period of rapid brain growth is sensitive, but not necessarily critical in the sense that any harm caused then is irreversible (Sands et al. 1979). In this view, rapid prenatal brain growth comprises no more than $10-15 \%$ of the total duration of the period of rapid brain growth, with the remainder being postnatal. Thus, in this perspective, parturition may not make a significant break in the biological development of the brain. A personal view is that the translation of the gestating organism into a person with social roles has potential biological effects on central nervous system development, and that it is unwise to ignore them. However, some of the major experimental studies of prenatal supplementation extend across the boundary of parturition and into the postnatal phase, and they will be considered under the heading of the postnatal phase.

In diverse studies, using different designs and outcome measures, malnutrition alone during this postnatal phase has not been shown to produce permanent mental impairment (Lloyd-Still, 1976a). In combination with a lack of intellectual and social stimulation, however, such malnutrition does appear to depress mental performance (Richardson, 1976; Grantham-McGregor et al. 1980; Chavez \& Martinez, 1975). This conclusion rests on an array of observations. In some studies, the nutritional deprivation was caused by clinical conditions in children who did not lack social stimulation: for instance, cystic fibrosis (Lloyd-Still, 1976a), coeliac disease (Valman, 1974), ileal resection, and cyanotic congenital heart disease (Silbert et al. 1969). These impairments of nutrition did not engender detectable mental impairment. In other studies episodes of acute nutritional failure in children reared in severely deprived environments gave rise to apparent deficits in mental performance, but these have seemed to recover with food and mental stimulation (Richardson, 1976; Grantham-McGregor et al. 1980). In further studies the effect of food supplementation was tested experimentally among children exposed to chronic malnutrition. These experimental studies have yielded equivocal responses (Freeman et al. 1980; Waber et al. 1981). In virtually all the experimental studies for which the necessary data are provided, however, the presence or absence of a response to supplementation can be seen to be mediated by the quality of the social environment.

One long-term and carefully conducted intervention study of the effect of early nutrition on cognition was conducted in four villages in Guatemala (Lechtig et al. 1974; Freeman et al. 1980). The diet of the villagers is described as mild to moderately deficient in protein and calories. In each of the four villages, women and children were encouraged to partake twice daily and ad libitum of a supplementary beverage. In two of the villages the beverage was a protein-calorie mixture; in the other two it contained no protein and fewer calories. At each visit the amount consumed by every individual was recorded. At each birthday, from 3 to 7 years of age, the children were evaluated on psychosocial and anthropometric measures, including family background and interaction.

Analyses of this study present problems; perhaps because there are many separate papers and even more authors, results and assertions from paper to paper are not entirely consistent. Exclusions of subjects are not all accounted for and could be confounding (Habicht $e t$ al. 1974b); sometimes longitudinal data are treated cross-sectionally with the same individuals appearing in several cells; the amount of supplementation is confounded with duration of gestation; home diet is measured but not analysed, etc. One special problem, recognized by the investigators, is that in the analysis the experimental design was abandoned in favour of a quasi-experimental one.

The relations of supplementation, physical growth, test scores and social indices were accounted for in a multivariate analysis. In the event, physical indices and social status indices both correlated significantly and independently with psychometric test scores, especially with language scores (Freeman et al. 1980). The total amount of supplementation of the mother during gestation and 
during lactation was considered separately from that of the child itself, and supplementation of both mother and child correlated with psychometric test scores and with growth. However, in the end, no significant postnatal effect of prenatal supplement consumption alone could be isolated; consumption by the children themselves correlated most strongly with test scores and physical growth. Because the analysis abandoned the experimental design and left the way open for subjects, as volunteers, to select themselves for the use of supplements, this result immediately raises the question: was the child who took more supplement livelier because of the food or was the livelier child the one who took the most supplement? We note that language was the test measure associated most consistently with supplement, as well as with social indices and physical growth. The language tests are said by the research workers to relate meaningfully to behaviour and social interaction outside the testing situation. This observation looks like a pointer to initiative in the child, which might have led to self-selection in the consumption of supplement.

The Guatemalan findings show that children who make use of food supplements will grow taller, and will do better on several cognitive tests, than those who do not. What the causal sequence is among these changes is not established. For how long the advantage of supplemented children will be maintained is also not yet known, but it was observed over several years of development. Finally, both the use and the effect of the nutritional supplement are seen to be mediated by the sociofamilial environment.

In another carefully designed intervention study in Bogota, Colombia (Waber et al. 1981), the effects of six blocked treatments could be compared: supplementation from the third trimester to 6 months postnatal; supplementation from the third trimester to 3 years; supplementation from 6 months postnatal to 3 years; no supplementation at all; and, finally, maternal education from birth to 3 years given to two experimental groups, one without supplementation, and another supplemented from the third trimester to 3 years. In Bogota, prenatal diet supplementation in the third trimester had a modest effect on birthweight, significant (on a one-tailed test, in our opinion unjustified) only in boys (Mora et al. 1979). We have already referred to the single postnatal effect of prenatal supplements in the foetal phase: at 15 days of age, supplemented infants exhibited a more rapid response decrement on a test of auditory habituation.

In the postnatal period diet supplementation influenced only motor measures, maternal education influenced only language, and there was no interaction between these effects. The advantage on motor measures of those supplemented through the third trimester and the first 6 months of postnatal life was short-lived. Thus, at 3 years of age, the children whose supplementation began postnatally at 6 months of age equalled the performance of those supplemented throughout the study period. In fact, the authors conclude that test scores reflect concurrent diet best. This study, like those in New York and Guatemala, offers no support for the concept of 'critical period'.

In sum, many gains from supplementation were modest, affected mainly motor functions, and were apparent only as long as the supplement was used. The Einstein:Corman-Escalona test, thought by the investigators to relate most closely to cognition, gave inconsistent results. We may conclude, with the investigators, that malnutrition probably decreased concurrent motivation and arousal, and that these effects may not be long-lasting.

The long-term observational studies of Cravioto et al. (1975) in a Mexican village provide the fullest adumbration of the connection between nutritional and social aspects of the environment and their combined effects on mental functioning. Cravioto et al. found that poor mental function was indeed associated with poor nutrition, but always and only in the presence of lack of social stimulation.

\section{CONCLUSIONS}

To sum up, specific dietary deficiencies and metabolic imbalances underlie a number of forms of mental retardation or depressed mental competence. As far as these are understood, they relate to a period very early in pregnancy - the peri-conceptional phase and the embryonic phase. With these disorders, the basis for prevention is much stronger than for treatment. Apart from these effects of early pregnancy, neither acute nor chronic malnutrition in the prenatal, foetal and the early 
postnatal phases has been shown to be a lasting cause of depressed mental competence, still less of clinical mental retardation. Where chronic nutritional deprivation is combined with social deprivation, however, cognitive performance in childhood is likely to be depressed. Whether such deficits persist into adulthood is not known, but examples of rehabilitation (Richardson, 1976; Grantham-McGregor et al. 1978, 1980; Hertzig et al. 1972; McLaren et al. 1973; Graham \& Adrianzen, 1971) make one reasonably optimistic that improvement could take place at older ages. The strongest hope for effective intervention, in our opinion, lies in the demonstrated and strong effect of social and educational stimulation conducted under good nutritional conditions (Garber, 1975; McKay et al. 1978; McKay \& McKay, 1981).

ZENA STEIN AND MERVYN SUSSER

\section{REFERENCES}

Antonov, A. N. (1947). Children born during the siege of Leningrad in 1942. Journal of Padiatrics 30, 250-259.

Blix, S., Hopfrander, Y. \& Vahlquist, B. (eds.) (1971). Famine. Swedish Nutrition Foundation Symposia 9. Almqvist and Weksells: Uppsala.

Burger, G. D. C., Drummond, J. C. \& Sandstead, H. R. (eds.) (1948). Malnutrition and Starvation in Western Netherlands: September 1944-July 1945. General State Printing Office: The Hague.

Chase, H. P. (1976). Undernutrition and growth and development of the human brain. In Malnutrition and Intellectual Development (ed. J. D. Lloyd-Still), pp. 14-38. Publishing Sciences Group: Littleton, Mass.

Chavez, A. \& Martinez, C. (1975). Nutrition and development of children from poor rural areas. V. Nutrition and behavioral development. Nutrition Reports International 11, 477-489.

Connolly, K. J., Pharaoh, P. O. \& Hetzel, B. (1979). Foetal iodine deficiency and motor performance during childhood. Lancet ii, $149-151$.

Cravioto, J. \& DeLicardie, E. (1975). Environment and nutrition deprivation in children with learning difficulties. In Perceptual and Learning Disabilities in Children, Vol. 2: Research and Theory (ed. W. Cruickshank and D. Hallahan), pp. 3-102. Syracuse University Press: Syracuse.

Edwards, J. H. (1958). Congenital malformations of the central nervous system in Scotland. British Journal of Preventive and Social Medicine 11, 115-130.

Eichmann, E. \& Gesenius, H. (1952). Die Missgeburtenzunahme in Berlin und Umgebung in den Nachkriegsjahren. Archiv für Gynaekologie 181, 168-184.

Elwood, J. H. (1972). Major central nervous system malformation notified in Northern Ireland 1964-1968. Developmental Medicine and Child Neurology 14, 731-739.

Freeman, H., Klein, R., Townsend, J. \& Lechtig, A. (1980). Nutrition and cognitive development among rural Guatemalan children. American Journal of Public Health 70, 1277-1285.

Gerber, H. L. (1975). Intervention in infancy: a developmental approach. In The Mentally Retarded and Society: $A$ Social Science Perspective (ed. M. J. Begab and S. A. Richardson), pp. 287-304. University Park Press: Baltimore.

Graham, G. G. \& Adrianzen, B. (1971). Growth, inheritance and environment. Pediatrics Research 5, 691-697.

Grantham-McGregor, S. M., Stewart, M. E. \& Desai, P. (1978). A new look at the assessment of mental development in young children recovering from severe malnutrition. Developmental Medicine and Child Neurology 20, 773-778.

Grantham-McGregor, S. M., Stewart, M. E. \& Schofeld, W. N. (1980). Effect of long-term psychosocial stimulation on mental development of severely malnourished children. Lancet ii, 785-789.

Gruenwald, P. (1967). Influence of environmental factors on foetal growth in man. Lancet i, 1026-1028.

Habicht, J. P., Lechtig, A., Yarbrough, C. \& Klein, R. E. (1974a). Maternal nutrition, birthweight and infant mortality in size at birth.
In Ciba Foundation Symposium 27 (new series), pp. 353-377. Excerpta Medica: Amsterdam.

Habicht, J. P., Yarbrough, C., Lechtig, A. \& Klein, R. (1974b). Relation of maternal supplementary feeding during pregnancy to birthweight and other sociological factors. In Nutrition and Fetal Development (ed. M. Winick), pp. 127-146. Current Concepts in Nutrition, Vol. 2. John Wiley \& Sons: New York.

Hertzig, M. E., Birch, H. G., Richardson, S. A. \& Tizard, J. (1972). Intellectual levels of school children severely malnourished during the first two years of life. Pediatrics 49, 814-823.

Hetzel, B. S. \& Hay, I. D. (1979). Thyroid function, iodine nutrition and fetal brain development. Clinical Endocrinology 11, 445-460.

Illsley, R. (1955). Social class selection and class differences in relation to stillbirths and infant deaths. British Medical Journal ii, $1520-1524$.

Jones, A. P. \& Friedman, M. 1. (1982). Obesity and adipocyte abnormalities in offspring of rats undernourished during pregnancy. Science 215, 1518-1519.

Keys, A., Brozek, J., Henschel, A., Mickelsen, O. \& Taylor, H. L. (1950). The Biology of Human Starvation, Vols. 1 and 2. University of Minnesota Press: Minneapolis.

Laurence, K. M., James, N., Miller, M. \& Campbell, H. (1980). Inverse risk of pregnancies complicated by fetal neural tube defects in mothers receiving poor diets and possible benefit of dietary counselling. British Medical Journal 281, 1592-1594.

Lenke, R. R. \& Levy, H. L. (1980). Maternal phenylketonuria and hyperphenylalaninemia: an international survey of the outcome of untreated and treated pregnancies. New England Journal of Medicine 302, 1202-1208.

Lloyd-Still, J. (1976a). Clinical studies on the effects of malnutrition during infancy and subsequent physical and intellectual development. In Malnutrition and Intellectual Development (ed. J. D. Lloyd-Still), pp. 103-159. Publishing Sciences Group: Littleton, Mass.

Lloyd-Still, J. D. (ed.) (1976b). Malnutrition and Intellectual Development. Publishing Sciences Group: Littleton, Mass.

McKay, H. \& McKay, A. (1981). The long-term effects of preschool nutritional health and educational attention. Prepared for the XVIII Interamerican Congress of Psychology, Santo Domingo, Puerto Rico, June.

McKay, H., Sinisterra, L., McKay, A., Gomez, H. \& Llorda, P. (1978). Improving cognitive ability in chronically deprived children. Science 20, 270-278.

McLaren, D. S., Yatkin, U. S., Kanawati, A. A., Sabbagh, S. \& Kadi, Z. (1973). The subsequent mental and physical development of rehabilitated marasmic infants. Journal of Mental Deficiency Research 17, 273-281.

Miller, E., Mare, J., Cloherty, J., Dunn, P., Gleason, R., Soeldner, J. \& Kiutzmiller, J. (1981). Elevated maternal hemoglobin A in early pregnancy and major congenital anomalies in infants of diabetic mothers. New England Journal of Medicine 304, 1331-1333. Mora, J. D., de Parades, B., Wagner, M., de Navano, L., Suescon, J., Christiansen, N. \& Herren, M. G. (1979). Nutritional 
supplementation and the outcome of pregnancy: I. Birthweight. American Journal of Clinical Nutrition 32, 455-462.

Mulinaire, J., Cordera, J. F. \& Erikson, J. D. (1981). Vitamin use and the occurrence of neural tube defects (abstract). American Journal of Epidemiology 114, 428.

Ravelli, G. P., Stein, Z. \& Susser, M. (1976), Obesity in young men after famine exposure in utero and early infancy. New England Journal of Medicine 295, 349-353.

Richardson, S. A. (1976). The relation of severe malnutrition in infancy to the intelligence of school children having different life histories. Pediatrics Research 10, 57-61.

Rush, D. (1982). Effects of changes in protein and calorie intake during pregnancy on the growth of the human fetus. In Effectiveness and Satisfaction in Antenatal Care (ed. M. Enkin and I. Chalmers), pp. 92-113. Spastics International Medical Publications/Heinemann: London.

Rush, D., Stein, Z. \& Susser, M. (1980). Diet in pregnancy: a randomized controlled trial of prenatal nutritional supplements. Birth Defects: Original Article Series 16 (3). Alan R. Liss: New York.

Sands, J., Dobbing, J. \& Gratix, C. (1979). Cell number and cell size: organ growth and development and the control of catch-up growth in rats. Lancet iii, 503-505.

Silbert, A., Wolff, P. H., Mayer, B., Rosenthal, A. \& Nadas, A. S. (1969). Cyanotic heart disease and psychological impairment. Pediatrics 43, 192.

Smith, C. A. (1947). Effects of wartime starvation in Holland on pregnancy and its products. American Journal of Obstetrics and Gynecology 53, 599-608.

Smithells, R. W., Sheppard, S., Schorah, C. J., Seller, M. J., Nevin, N. C., Harris, R., Read, A. O. \& Fielding, D. W. (1980). Possible prevention of neural-tube defects by periconceptual vitamin supplementation. Lancet i, 339-340.
Sorokin, P. A. (1975). Hunger as a Factor in Human Affairs (transt. E. P. Sorokin). University of Florida Press: Miami.

Stein, Z. A. \& Kassab, H. (1970). Nutrition. In Mental Retardation, Vol. 2 (ed. J. Wortis), pp. 92-116. Grune \& Stratton: New York. Stein, Z. A. \& Susser, M. W. (1976). Maternal starvation and birth defects. In Birth Defects: Risks and Consequences (ed. E. B. Hook), pp. 205-220. Academic Press: New York.

Stein, Z. A., Susser, M. W., Saenger, G. \& Marolla, F. A. (1975). Famine and Human Development: The Dutch Hunger Winter of 1944/45. Oxford University Press: New York.

Susser, M. W. \& Watson, W. (1971). Sociology in Medicine (2nd edn). Oxford University Press: London.

Thomson, A. M. (1956). The diagnosis of malnutrition in wellnourished communities. American Journal of Clinical Nutrition 4, 647-654

Valman, H. B. (1974). Intelligence after malnutrition caused by neonatal resection of ileum. Lancet $i, 425$.

Waber, D. P., Vuori-Christiansen, L., Ortiz, N., Clement, J. R. Christiansen, N. E., Mora, J. O., Reed, R. B. \& Herrera, M. G. (1981). Nutritional supplementation, maternal education, and cognitive development of infants at risk of malnutrition. American Journal of Clinical Nutrition 34, 807-813.

Widdowson, E. M. (1951). Mental contentment and physical growth. Lancet i, 1316-1318.

Winick, M. (ed.) (1979). Studies of the Jewish Physicians in the Warsaw Ghetto: Hunger Disease (transl. M. Osnos). Current Concepts in Nutrition, Vol. 7. Wiley Interscience: New York.

Winick, M. Noble; A. (1966). Cellular response in rats during malnutrition of various ages. Journal of Nutrition 89, 300-306.

Yen, S. \& MacMahon, B. (1968). Genetics of anencephaly and spina bifida? Lancet ii, 623-626. 